International Journal of Management \& Entrepreneurship Research.

P-ISSN: 2664-3588, E-ISSN: 2664-3596.

Vol. 1(5), pp. 174-205 August, 2019.

Fair East Publishers.

Journal Homepage: www.fepbl.com/index.php/ijmer.

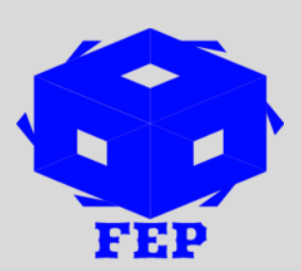

\title{
CONFLICTS AS AN EFFECT OF ALCOHOL CONSUMPTION \\ IN VERY POOR COUNTRIES: AN EXPLORATORY RESEARCH ON EXPERIENCED CHRISTIAN CONSUMERS IN BURKINA FASO.
}

\author{
Dr. Théophile Bindeouè Nasse $\mathrm{i}^{1,2,3}$. \\ ${ }^{1}$ Department of Governance and Management, University for Development Studies, Ghana. \\ ${ }^{2}$ University Institute of Initial and Continuing Education (IUFIC), Ouaga 2 University, Burkina Faso. \\ ${ }^{3}$ Faculty of Economic and Management Sciences, Saint Thomas D’Aquin University, Burkina Faso.
}

*Corresponding Author: Dr. Théophile Bindeouè Nasse.

Corresponding Author Email: nassetheophile2009@gmail.com

Article Received: 05-07-19 Accepted: 25-08-19 Published: 05-09-19.

Licensing Details: Author retains the right of this article. The article is distributed under the terms of the Creative Commons Attribution-Non Commercial 4.0 License (http://www.creativecommons.org/licences/by-nc/4.0/) which permits non-commercial use, reproduction and distribution of the work without further permission provided the original work is attributed as specified on the Journal open access page.

\section{ABSTRACT}

The topic of alcohol consumption and conflicts has been explored in several context not only because consumers do not have a good consumption culture, but also because alcohol consumption often leads to social violence (Nasse, 2018; Nasse, Ouédraogo \& Diop, 2019). Most of the studies on the topic are done in other contexts. Little research on the subject has been conducted in Burkina Faso. Therefore, this research aims to explore the concepts of alcohol consumption and conflicts in the context. Burkina Faso is a country where religion plays a significant role. However, alcohol consumption is increasing (Sow, 2005), even among consumers who are believers, but ignorance in the sector of marketing seems to be a barrier that favors unethical consumption. The research is a mixed approach. The qualitative data collection is performed with a voice recorder by the means of some semi-structured interviews. Then, the qualitative data is transcribed by hand. The quantitative data is collected by the means of a questionnaire. The qualitative data and the quantitative data are performed using sphinx IQ software. The results show that social class moderates the relationship between alcohol consumption and conflicts.

Keywords: Alcohol consumption, Conflicts, Household conflicts, Street conflicts, Religious conflicts, Development, Management. 


\section{INTRODUCTION}

First of all, researches on religion and consumption have been done everywhere in the world and in the context of Africa (Andaleeb, 1993; Bailey \& Sood, 1993; Berger, 1997; Bagozzi, Abe, Wong \& Bergami, 2000; Heiman, Zilberman \& Gordon, 2001; Fam, Waller \& Erdogan, 2002; De Mooij, 2003; Ger, 2005; Lord \& Putrevu, 2005; Khalla, 2006; Mokhlis, 2006; Cleveland, Laroche \& Hallab, 2010; Patel, 2010; Ruzeviciute \& Ruzevicius, 2011; Mansori, 2012; Diop, 2012; Porter, 2013; Benabdallah \& Jolibert, 2013; Nurbasari, 2015; Nasse, Ouédraogo \& Diop, 2016; Morsy \& Néji, 2016; Nasse, 2018). In the Western context, one of the studies that underlines alcohol consumption and violence behavior is made by Amankwaa, Reed, and Owens (2012). However, in Burkina Faso there is not a deeper knowledge on alcohol consumption and conflicts in term of research, though the phenomenon is a daily challenge that people face. Marketing practices in the African context are recent; then most of the research topics on management are directed to other sectors because making a research on consumption and religious consumers seems to be a taboo (Nasse $\&$ al., 2016). In addition, conducting a research on the concepts of alcohol consumption and conflicts in the context of Burkina Faso is meaningful as previous studies on consumption in other contexts have focused on such concepts. Therefore, this is an exploratory research in the context of Burkina Faso, and there is a necessity to verify other context findings in the African context. Management and marketing in the Western countries and in the Asian countries have brought out some results; and several studies have allowed the assessment of different marketing theories about culture and consumption to be reassured that cultural consumption patterns are not the same (Usinier, 2000 ; Diop, 2004 ; Nasse, 2018). Hence, the present research topic is on alcohol consumption and conflicts. This research aims to provide managerial solutions to companies, to adapt alcohol to consumption, to the core needs and to the expectations of consumers. In Burkina Faso, one can observe an increasing rate of alcohol consumption. Indeed, some previous studies have pointed out that alcoholic drinks are among the events of daily life (Bazié, 2011; Nasse, 2018; Nasse \& al., 2019) and that they have a medical function in such a sociocultural context (Nasse $\&$ al., 2016; Nasse, 2018). Today, Burkina Faso is composed of $23.2 \%$ of Christians with $19 \%$ of Catholics and $4.2 \%$ of evangelical Christians (INSD, 2010). In Burkina Faso, an observation is that the revealed religions are in favor of non-alcoholic drinks consumption, while companies are promoting the alcoholic drinks consumption (Nasse \& al., 2016; Nasse, 2018). Nevertheless, the real expectations and the core needs of some consumers are sometimes ignored due to the lack of rigorous segmentation. Religious beliefs seems to promote ethical consumption and they appear to be a barrier to the business and to the consumption of alcoholic drinks. The lack of appropriate innovation in the marketing of alcohol sector seems to be another barrier to the consumption of alcoholic drinks in the context.

Thus, the research question is: How and why Christian consumers should contribute to reducing conflictual situations in relation with alcohol consumption?

This research question is structured on the following fundamental questions:

1. What are the relationships between alcohol consumption and street conflicts?

2. What are the relationships between alcohol consumption and household conflicts?

3. What are the relationships between alcohol consumption religious conflicts? 
There is a general objective and there are some specific objectives to this research.

The general objective is to show the association between alcohol consumption and conflicts in the context of Burkina Faso. The first specific objective is to analyze the relationships between alcohol consumption and street conflicts. The second specific objective is to identify the relationships between alcohol consumption and the household conflicts in the context of Burkina Faso. The third specific objective is to determine the relationships between alcohol consumption and religious conflicts in the context of Burkina Faso.

\section{LITERATURE REVIEW.}

The literature review is focused on the analysis of different theories and the different concepts which are in line with the present research.

\section{* The different theories of the research.}

There are different types of theories.

-The sustainable development theory of consumption: Some authors like Van den Bergh and Nijkamp (1991), Bidan (2010), Nasse et al. (2016) have stressed that consumer behavior should not impede to the welfare of the future generations. Thus, there is a need to have a conscious and ethical consumption behavior. This help to protect the environment in which people are leaving in; and it is a way to preserve it for future generations. In some extend, these authors fail to bring out that consumer behavior may also be influenced by some needs or traits that are culture bounded.

-The Culturalist theory of consumption: However, Jung and Kau (2004), and Essoo Dibb (2004), Mokhlis (2006), Mokhlis (2009), Mokhlis (2010), Alam, Mohd and Hisham (2011), Nayeem (2012), Mustafar and Borhan (2013), Bazzeem (2015), Esteban (2015), Nurbasari (2015), Campanella (2016), show that the behavior of a given consumer has its roots within the consumer culture. For these researchers, consumer behavior is mainly influenced by culture. Understanding the consumption dimensions means that one should go back into the sociocultural context within which the consumer lives.

-The economic theory of consumption : Simon (2000), Matthew and Morrison (2003), Ouédraogo (2007), Kitchathorn (2009), Nasse (2012), Shamba and Livian (2014), Van Laethem and Body (2008), Nasse (2015) argue in support of the economic theory of consumer behavior, by stating that a consumer will repurchase some products when these products have the greatest value in terms of quality or when these products give an absolute satisfaction at a reasonable price as compared to their qualities. Thus, the consumer relies on some economic criteria to make his or her choices. Thus, the economists should also take into consideration that some emotional factors may affect consumption.

-Frustration-aggression theory of conflicts: Authors like Dollard, Miller, Doob, Mowrer, and Sears (1939), Nasse et al. (2016), Marfo and Musah (2018) argue in the sense of the frustrationaggression theory of conflicts. These authors state that some conflicts are generated due to the accumulation of frustration by some given individuals or some groups. This accumulation of frustration draws the individual then to become aggressive and violent what leads to a conflictual 
situation. However, conflicts are not always due to frustration or aggression, but conflicts are also learnt in the society.

-Social learning theory of conflicts: Fred-Mensah (2005), Bandura (1977) focus their arguments on the social learning theory of conflicts. For these authors, conflicts are learnt in the social context. They argue that it is rather the social environment that teaches people to become aggressive or violent. Thus, conflicts are learnt, imitated and reproduced but intrapersonal conflicts are often difficult to imitate due to their intangibility.

\section{* The research concepts.}

The research aims to define the concepts that are in line with the topic.

-The concept of conflict: The concept of conflict has been defined by several authors. In the western context, Goodhand and Hume (2009) have defined conflict as a disagreement resulting from individuals or groups that differ in behavior, beliefs, and values or in needs. The concept of conflict as approched by Goodhand and Hume is limited by the fact that it does not involve the violent aspect of conflict, but it rather shows conflict to be a mere disagreement. In the African context, the concept of conflict has been approached in a religious environment by Nasse et al. (2016), as a misunderstanding between individuals and groups due to a given misbehavior that affect a given religious community or group. The concept of conflict as approached by Nasse et al. (2016) depicts the social violence aspect of conflict and that is why recommendations have drawn the attention of political authorities and managers to help prevent these conflicts. In Ghana the concept of conflict has been defined by Awedoba (2012) as a relationship between two or more parties centered on differences, disagreement and some issues of common interest or concern. In the Middle East context, Al-Hyari, Alnsour, Al-Weshah, and Haffar (2012) has demonstrated that the consumer behavior in Saudi Arabia, has a link with religiosity, and that the sales of insane products generates conflicts which are in a form of products boycotting.

-The concept of alcohol: The concept of alcohol can be defined in several ways. The concept of alcohol is defined by the French dictionary Larousse as a drink or a juice that has undergone a process of fermentation. However, the concept can also be understood to be any type of drink that contains alcohol. For some authors like, Amankwaa, Reed and Owens (2012), Nasse et al. (2016) alcohol refers to the industrial fermented drinks that are sold or consumed. However, in this research the concept of alcohol refers to any drink that has been fermented either through some traditional ways of production or through some modern or industrial ways of production.

- The concept of consumption: The Concept of consumption has also been approached by several authors. Consumption has been approached by Bazié (2011), Amankwaa et al. (2012), Nasse et al. (2016), Nasse (2018) as the action of drinking a given drink. However, for some authors such as Mokhlis (2009), Diop (2012), Kibora (2015), consumption refers to the action of using and of eating a particular food. In this research the concept of consumption is understood to be the action of using or drinking a given beverage.

-The concept of alcohol consumption: The concept of alcohol consumption is approched by Amankwaa, Reed, and Owens (2012) as the drinking of industrial alcoholic drinks. In Africa and particularly in Burkina Faso, it is agreed by the research of Nasse et al. (2016) that the concept of alcohol consumption is also the drinking of industrial alcoholic drinks. Still, in the context of 
Burkina Faso, Bazié (2011) has approached the concept of alcohol consumption to be the drinking of traditional alcohol beverages, in his study on understanding communication in the traditional environment, and the sociocultural characteristics of different ethnic groups.

From the literature review some researchers have underlined that alcohol consumption (Amankwaa \& al., 2012; Nasse \& al., 2016) leads to social conflictual situation. The proposed solutions for such conflictual situations by previous authors are that there should be a consideration of culture differences, religious beliefs and the implication of political leaders and managers. However, the conceptual framework here shows that the alcohol consumption in a religious context or environment leads to conflictual situations either between religious groups or between individuals or within a given religious group. The framework seeks to explain how consumers contribute to generate conflicts through alcohol consumption in the light of the following relevant theories such as the culturalist theory, frustration-aggression theory, the social learning theory, and the economic theory. The proposed solutions in this research, are the implication of political authorities, managers, religious leaders, traditional leaders and educators.

\section{MATERIALS AND METHOD}

The research is based on a post-positivist posture. The approach is mixed.

-Research instruments: This section focuses on the description of the interview guide and questionnaire. For the qualitative research, it focuses on indicating the number of themes, the focus of the themes, their provenance. Qualitative research will be conducted through one type of instrument. The instrument is a semi-structured interview guide for the experienced consumer of alcoholic beverages. The interview guide is pre-tested with 10 respondents and then it is corrected to make it more understandable to respondents. The number of themes is eleven (11). These themes are constructed using the different variables identified during the literature review. To make content analysis more relevant a grid is also used. For the quantitative research, it focuses on the number of questions and the source of the questionnaire used. The questionnaire consists of twenty-six (6) questions constructed from the verbatim of the qualitative research.

-Research procedure: This section outlines sampling strategies to identify participants, locations of interviews, and how data is recorded. According to authors, such as Morse (1991) and Coyne (1997), there are four different types of sampling strategies for qualitative research: targeted sampling, choice sampling, voluntary sampling, and sampling of the entire population. However, for Marshall (1996), there are three (3) different types of qualitative sampling strategies: convenience sampling, targeted sampling and theoretical sampling. The sampling technique that is used in this research is purposeful sampling because of its common use by researchers and because of a lack of sufficient resources and time to carry out research for a very long time. For Marshall (1996: 523), purposeful sampling or judgment sampling is a widely used sampling technique of selecting the most experienced respondents to answer the research question. The qualitative sampling strategy for locating participants consists of identifying the drinking places where experienced alcohol users are and asking for an interview during their free time. Interviews are conducted at a location chosen by the participant, where there is especially less noise. Research participants are invited to invite other dedicated participants whom they know, who fulfill the research criteria, and who agree to participate regularly in this research. 
This qualitative research is conducted using a semi-structured interview guide for respondents who are experienced consumers of alcoholic beverages. The recordings of the interviews are made in French with a voice recorder. However, it should be noted that some respondents did not accept the voice recorder and the interview data was collected on paper or was captured on a computer. The recorded data is transcribed by hand using the audio software. The criterion of "saturation" is the criterion used to stop the data collection; because usually the last interview does not provide more information. The quantitative sampling strategy consists of using a simple random sampling technique due to a lack of time and a lack of resources. The questionnaire is pre-tested with the consumers of alcoholic beverages. This first test is done on a sample of 50 respondents. The pre-test results is used to draft a final version of the questionnaire. The designed questionnaire is administered again to the consumers of alcoholic beverages and recorded again on a paper. This sample is a subset of the studied population. To set the sample size, the following mathematic formula is used: $n=(p)(1-p) /(e / Z)^{2}$, where, p represents the selected proportion of an attribute, for example gender. Here, assuming 50-50 female to male ratio, $\mathrm{p}=0.50$ or $50 \%$; e represents the level of precision or accuracy set for this research, here $7 \%$, and $\mathrm{Z}$ is the number related to degree of confidence in this case $\mathrm{Z}=1.96$ or $95 \%$ confidence (Ganassali, 2009: 51; Hejase and Hejase, 2013: 231;). Then, this case the formula becomes: $\mathrm{n}=$ $(0.5 \times(1-0.5)) /(\mathrm{e} / 1.96)^{2}=0.25 /(\mathrm{e} / 1.96)^{2}$. The number of people to interview for a maximum error of $7.0 \%$, then is $n=0.25 /(0.07 / 1.96)^{2}=196$ people. A sample of 196 people is enough for a 7 point error estimate. Once the sample determined, data collection is done through a questionnaire on a paper and it is filled by the consumers. The total number of respondents is 241.

- Research context: The country where the research is conducted is Burkina Faso. The research area includes the main city of Ouagadougou, for a period of 10 months.

- Research Participants: Participants are considered according to their age, gender, religion, educational level, marital status, occupation, and social class. First, the age of participants ranges from 18 to over 55 years old. Second, the gender of the participants includes Christian men and women. Third, the educational level of participants includes illiterates, primary school level, secondary school level or university level. For the illiterate and primary school level participants, the local languages are used to enable them to participate because of their impossibility to master French. Finally, the participants are from different professions and different social classes.

-Validity of the research: The different items of the variables are measured (see table 1 below) using the alpha of Cronbach. The research instruments should allow the researcher to measure the phenomenon that is to be measured (Carricano \& al., 2010).

Table 1

Values of the alphas of Cronbach for the variables.

\begin{tabular}{lcc} 
Variable & Number of items & Alpha of Cronbach value \\
\hline Alcohol consumption & 4 & 0.77 \\
\hline Conflicts & 12 & 0.90 \\
\hline Household conflicts & 4 & 0.82 \\
\hline Street conflicts & 4 & 0.77 \\
\hline Religious conflicts & 4 & 0.79
\end{tabular}


- Data analysis: In this research, the qualitative data is transcribed by hand using an audio software. Then, the qualitative data is processed using the qualitative version of Sphinx IQ. A content analysis of the qualitative data is made. The quantitative data is also processed thanks to the quantitative version of Sphinx IQ.

- Ethical implications: In this research, there are some ethical measures to be taken into account as what is normal to be considered for a scientific research (Creswell, 2009). In this research in order to increase participation, respondents are not requested to give their names, and information given by the respondents is kept confidential (Nasse, 2018).

\section{-Research propositions and research model.}

Some variables and hypotheses (or propositions) are derived from the above literature review:

DH1 or P1: There is a relationship between alcohol consumption and street conflicts.

DH2 or P2: There is a relationship between alcohol consumption and household conflicts.

DH or P3: There is a relationship between alcohol consumption and religious conflicts.

Figure 1: Research Model

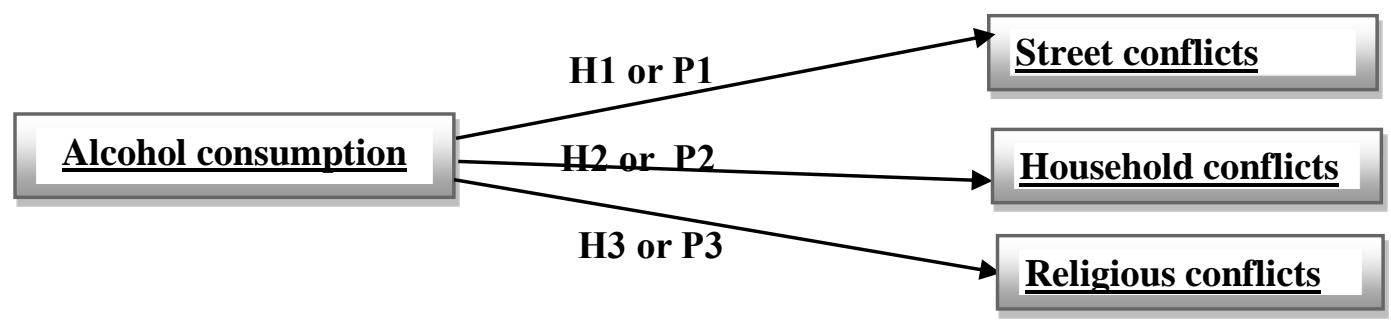

(Source: Nasse, research model, 2019.)

\section{Results analysis.}

\section{RESULTS AND DISCUSSION.}

In this section there are the qualitative results and the quantitative results.

\section{Qualitative results analysis.}

- Descriptive statistics.

Descriptive statistics are statistics that describe the fundamental aspects of the collected data by providing a simple information on the measures of the features (Anderson, Sweeney, Williams, Camm and Cochran, 2015). The descriptive statistics cover the religious affiliation of the respondents, the age of the respondents, the profession of the respondents, the social class of the respondent, the gender of the respondent, the marital status of the respondents, level of education 
of the respondents and the nationality of the respondents. The total number of the respondents is 23. There are seventeen (17) men and six (6) women. Among them there are some unemployed, some public employees, and some private employees. The respondents' level of education goes from illiterate to primary school, secondary school and university levels. The descriptive statistics starts with the religious affiliation of the respondents. In term of religious affiliation, the respondents were mainly from Apostolic Church, Assembly of God Church, Baptist Church, Catholic Church and the International Center of Evangelization Church. The field data shows that $04.34 \%$ of the respondents are from Apostolic Church, 13.04\% of the respondents are from Assembly of God Church, 26.08\% of the respondents are from Baptist Church, $47.82 \%$ of the respondents are from Catholic Church and 08.69\% are from the International Center of Evangelization. The results are presented in the following table 2.

Table 2

Religious affiliation of respondents.

\begin{tabular}{|c|c|c|c|}
\hline Religious affiliation of respondents & Frequency & $\underline{\text { Relative frequency }}$ & Percentage \\
\hline Apostolic & 1 & 0.0434 & $04.34 \%$ \\
\hline Assembly of God & 3 & 0.1304 & $13.04 \%$ \\
\hline Baptist & 6 & 0.2608 & $26.08 \%$ \\
\hline Roman catholic & 11 & 0.4782 & $47.82 \%$ \\
\hline International Center of Evangelisation & 2 & 0.0869 & $08.69 \%$ \\
\hline Total & 23 & 1 & $100 \%$ \\
\hline
\end{tabular}

(Source: Nasse, data analysis, 2019.)

Table 3

Statistics related to the socio-demographic variables.

\begin{tabular}{|c|c|c|c|c|}
\hline \multicolumn{2}{|c|}{ Socio-demographic variables } & Frequency & Relative frequency & Percentage \\
\hline \multirow{4}{*}{ Age } & $18-25$ & 6 & 0.2608 & $26.08 \%$ \\
\hline & $26-35$ & 7 & 0.3043 & $30.43 \%$ \\
\hline & $36-45$ & 5 & 0.2173 & $21.73 \%$ \\
\hline & $46-$ and above & 5 & 0.2173 & $21.73 \%$ \\
\hline \multirow[t]{2}{*}{ Gender } & Women & 17 & 0.7391 & 73.91\% \\
\hline & Men & 6 & 0.2609 & $26.09 \%$ \\
\hline \multirow{4}{*}{ Marital status } & Single & 12 & 0.5217 & $52.17 \%$ \\
\hline & Married & 11 & 0.4783 & $47.83 \%$ \\
\hline & Divorced & 0 & 0.0 & $\mathbf{0 . 0 \%}$ \\
\hline & Public employees & 4 & 0.1739 & $17.39 \%$ \\
\hline \multirow{3}{*}{ Profession } & Private employees & 15 & 0.6521 & $65.21 \%$ \\
\hline & Unemployed & 4 & 0.1739 & $17.39 \%$ \\
\hline & Very poor & 0 & 0.0 & $00 \%$ \\
\hline \multirow{3}{*}{ Social class } & Poor & 9 & 0.3913 & 39.13\% \\
\hline & Rich & 11 & 0.4782 & $47.82 \%$ \\
\hline & Very rich & 3 & 0.1304 & $13.04 \%$ \\
\hline \multirow{4}{*}{ Education level } & Illiterate & 4 & 0.1739 & $17.39 \%$ \\
\hline & Primary school level & 1 & 0.0434 & $04.34 \%$ \\
\hline & Secondary school level & 5 & 0.2173 & $21.73 \%$ \\
\hline & University level & 13 & 0.5652 & $56.52 \%$ \\
\hline \multirow{2}{*}{ City } & Ouagadougou & 23 & 1 & $100 \%$ \\
\hline & Out of Ouagadougou & 0 & 0.0 & $0.0 \%$ \\
\hline \multirow[t]{2}{*}{ Nationality } & Burkinabe & 22 & 0.9565 & $95.65 \%$ \\
\hline & Non Burkinabe & 1 & 0.0434 & $04.34 \%$ \\
\hline
\end{tabular}

(Source, Nasse, data analysis, 2019) 
The results on the above table 3. The age range is from 18 to 46 and above. However, the very old consumers are not numerous in the research for several reasons. The very old people tend to be much occupied about life issues and there are more young people in drinking spots than very old people. Another is that alcohol consumption tends to be a fashion for the youth who follow life trends and who are more numerous in term of statistics. That is why the average age is 31.17. Thus, $\mathbf{2 6 . 0 8 \%}$ of the respondents are between 18 and 25 years old, $\mathbf{3 0 . 4 3 \%}$ of the respondents are between 26 and 35 years old, $\mathbf{2 1 . 7 3 \%}$ of the respondents are between 36 and 45 years old, and $\mathbf{2 1 . 7 3 \%}$ of the respondents are between 46 and more. For further, concerning the profession of the respondents, $\mathbf{1 7 . 3 9 \%}$ are public employees, $\mathbf{6 5 . 2 1 \%}$ are private employees, and $\mathbf{1 7 . 3 9 \%}$ are unemployed. In addition, concerning the social class of the respondents, $\mathbf{3 9 . 1 3 \%}$ are poor, $\mathbf{4 7 . 8 2 \%}$ are rich, and $\mathbf{1 3 . 0 4 \%}$ of the respondents are very rich. Moreover, concerning the gender of the respondents, $\mathbf{7 3 . 9 1 \%}$ are men, and $\mathbf{2 6 . 0 9 \%}$ are women. Besides, concerning the marital status of the respondents, $\mathbf{5 2 . 1 7 \%}$ are single, and $\mathbf{4 7 . 8 3 \%}$ are married. About the level of education of the respondents, $\mathbf{1 7 . 3 9 \%}$ of them are illiterate, $\mathbf{0 4 . 3 4 \%}$ have the primary school level, $\mathbf{2 1 . 7 3 \%}$ have the secondary school level and $\mathbf{5 6 . 5 2 \%}$ have the University level. After, the lemmatization of the data, the lexicon gives the most frequent words in the answers. It is composed of words such as "alcohol', “conflicts", “diseases", “accidents", "wives", "liver", "death", "husbands" and "blood" (see the following table 4). These words are referring to a different emotional states among which one can list: sadness, unhappiness, troubles, violence, severe pains, and sorrows.

Table 4
Most frequent words in the answers.
\begin{tabular}{lc} 
Words & Frequency \\
\hline Alcohol & 528 \\
Conflicts & 218 \\
Diseases & 19 \\
Accident & 14 \\
Wives & 11 \\
Liver & 9 \\
Death & 6 \\
Husbands & 6 \\
Blood & 5
\end{tabular}

(Source: Nasse, data analysis, 2019.)

In the context of Burkina Faso, alcohol consumption causes different source of conflicts among which religious conflicts, household conflicts, street conflicts. In addition, alcohol consumption generates multiples diseases such as high blood pressure, liver disease, kidney disease, cancer, cardiovascular diseases. Some consumers who are victims of such diseases or who died from such diseases are sometimes from the very poor class or the poor class. A first observation is that their purchasing power do not allow them to buy the best alcoholic drinks as they are expensive; 
therefore they consume counterfeit alcohol that is very cheap. A second observation is that they often consume these beverages with hunger as they do not have sufficient food. A third observation is that when they are sick they do not have the means to go to hospital for an appropriate medical care. Another explanation is that these poor consumers do not get access to appropriate medical treatment because of the poor conditions and the insufficiency of health facilities. Alcohol consumption is also a source of multiple accidents on the roads where some cases of death often occur. The following classification shows the seven (7) top and most popular alcoholic drinks listed by consumers: Brakina (13.74\%), Beaufort (12.97\%), Sobbra (10.68\%), Wine (10.68\%), Dolo (9.16\%), Castel (7.63\%), and Flag (6.10\%) (See the following table 5).

Table 5

Classification of the most popular alcohol drinks.

\begin{tabular}{lcc}
\multicolumn{3}{c}{ Response rate: 100.0\% } \\
\hline Drink name & Frequency & Percentage \\
\hline Brakina & $\mathbf{1 8}$ & $\mathbf{1 3 . 7 4 \%}$ \\
\hline Beaufort & $\mathbf{1 7}$ & $\mathbf{1 2 . 9 7 \%}$ \\
\hline Sobbra & $\mathbf{1 4}$ & $\mathbf{1 0 . 6 8 \%}$ \\
\hline Wine & $\mathbf{1 4}$ & $\mathbf{1 0 . 6 8 \%}$ \\
Dolo & $\mathbf{1 2}$ & $\mathbf{9 . 1 6 \%}$ \\
Castel & $\mathbf{1 0}$ & $\mathbf{7 . 6 3 \%}$ \\
Flag & $\mathbf{8}$ & $\mathbf{6 . 1 0 \%}$ \\
\hline Pastis & $\mathbf{7}$ & $\mathbf{5 . 3 4 \%}$ \\
\hline Martini & $\mathbf{6}$ & $\mathbf{4 . 5 8 \%}$ \\
\hline Vodka & $\mathbf{6}$ & $\mathbf{4 . 5 8 \%}$ \\
\hline Eperon & $\mathbf{5}$ & $\mathbf{3 . 8 1 \%}$ \\
\hline Fighter & $\mathbf{4}$ & $\mathbf{3 . 0 5 \%}$ \\
\hline Johnny walker & $\mathbf{4}$ & $\mathbf{3 . 0 5 \%}$ \\
\hline Shandy & $\mathbf{4}$ & $\mathbf{3 . 0 5 \%}$ \\
\hline Vieux menthos & $\mathbf{4}$ & $\mathbf{3 . 0 5 \%}$ \\
\hline Jin & $\mathbf{3}$ & $\mathbf{2 . 2 9 \%}$ \\
\hline Sopal & $\mathbf{3}$ & $\mathbf{2 . 2 9 \%}$ \\
\hline Alomo & $\mathbf{2}$ & $\mathbf{1 . 5 2 \%}$ \\
\hline Red label & $\mathbf{2}$ & $\mathbf{1 . 5 2 \%}$ \\
\hline Alcoholic malta & $\mathbf{2}$ & $\mathbf{1 . 5 2 \%}$ \\
\hline Total & $\mathbf{1 3 1}$ & $\mathbf{1 0 0 \%}$ \\
\hline Total drink types & $\mathbf{2 0}$ & $\mathbf{1 0 0 \%}$ \\
\hline Total number of respondents & $\mathbf{1 0 0 \%}$ \\
\hline
\end{tabular}

(Source: Nasse, data analysis, 2019.)

'Brakina' is at the top given because it is a national drink which is well known and appreciated for some years. 'Brakina' has gained in term of popularity for some years before the other 
alcohol drinks. It is also a drink that is associated to female drinkers in the past; 'Beaufort' is also at the top because it is well known and because of its meaning in French that is composed of the words "beau" which means "in-law" and "fort" which means "strong, powerful". Thus, 'Beaufort' means "'strong in-law', " powerful in-law', and people do consume it for prestigeous effects. 'Sobbra' is also well known given the fact that it is a national drink which is well known and appreciated for some years. It was associated to male drinkers. On one hand, the mapping of the data on alcohol consumption and its positive aspects gives the following table 6 and the following figure 1 of the cognitive map.

Table 6

Words most frequently associated with alcohol consumption and its positive aspects.

\begin{tabular}{|c|c|c|c|c|c|}
\hline & drink & For & To & It & heals \\
\hline & alcohol (19) & alcohol (12) & relaxation (14) & creates (13) & alcohol (12) \\
Alcohol & relaxation (13) & relaxation (12) & alcohol (13) & alcohol (12) & diseases (12) \\
consumption & creates (12) & helps (12) & helps (12) & job (12) & healing (12) \\
and its positive & diseases (12) & & & & \\
aspects & $\begin{array}{c}\text { healing (12) } \\
\text { helps (12) }\end{array}$ & & & & \\
& relationships (12) & & & & \\
\hline
\end{tabular}

(Source: Nasse, data analysis, 2019.)

The above table 6 data show the systematic frequency of the words. These words produce a sense by revealing that alcohol, relationships, relaxation and disease healing are closely related. Thus, alcohol consumption creates relationships, friendships, relaxation and healing what attracts consumers to consume it. The following figure 1 representing cognitive mapping also shows this closeness between the alcohol consumption and relationships, relaxation, job creation, and diseases healing.

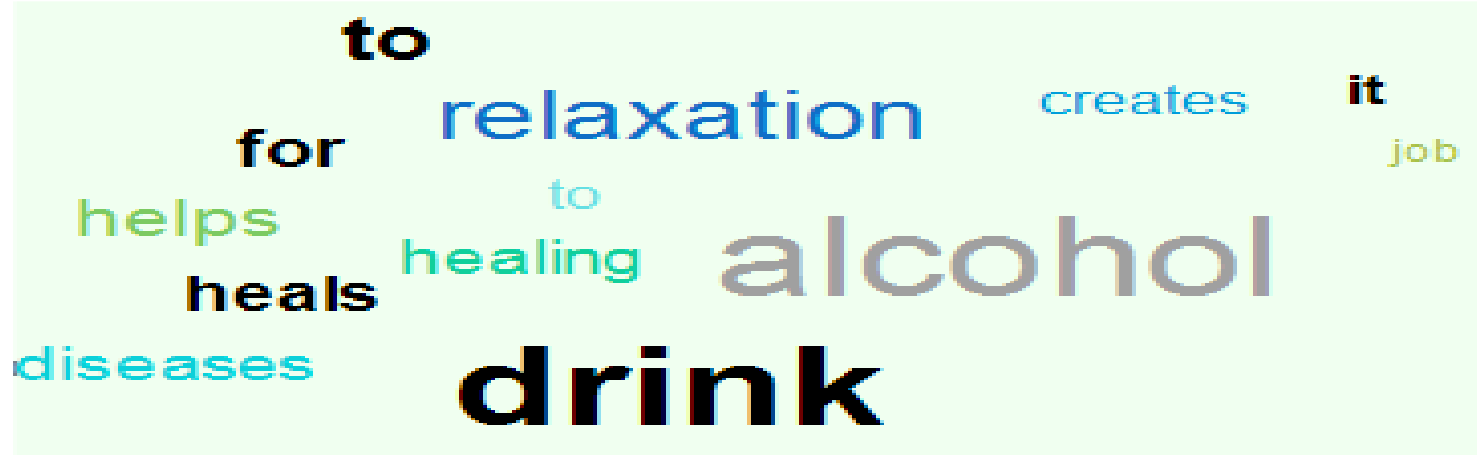

relationships

Figure 1: Cognitive mapping of the words most frequently associated with alcohol consumption and its positive aspects. 
On the other hand, the mapping of the data on alcohol consumption and its negative aspects gives the following table 7 and the following figure 2 of the cognitive map.

Table 7

Words most frequently associated with alcohol consumption and its negative aspects.

\begin{tabular}{|c|c|c|c|c|c|}
\hline & Alcohol & Conflicts & Diseases & Creates & Generates \\
\hline & alcohol (21) & conflicts (16) & diseases (16) & alcohol (14) & alcohol (14) \\
Alcohol consumption and & conflicts (15) & alcohol (15) & alcohol (15) & creates (14) & generates (14) \\
its negative aspects & $\begin{array}{c}\text { diseases (15) } \\
\text { creates (14) }\end{array}$ & $\begin{array}{c}\text { diseases (12) } \\
\text { generates (12) }\end{array}$ & $\begin{array}{c}\text { conflicts (12) } \\
\text { creates (12) }\end{array}$ & diseases (12) & conflicts (12) \\
& generates (14) & accident (12) & & & \\
& & & \\
\hline
\end{tabular}

(Source: Nasse, data analysis, 2019.)

The above table 7 data show the systematic frequency of the words. These words produce a sense by revealing that alcohol, conflicts, and accidents are closely related. This can also be interpreted in the sense that some consumers who consume alcohol sometimes causes accidents on the roads and that situation generates some conflictual situations between the victims and non-victims. The following figure 2 representing cognitive mapping also shows this closeness between alcohol consumption, accidents and conflicts. In addition, it shows this closeness between alcohol consumption and diseases. Finally, it also shows this closeness between alcohol consumption and conflicts.

\section{generates}

generates

\section{croattos alcohol}

\section{creates}

\section{diseases

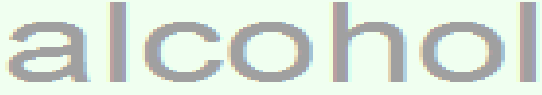 \\ diseases}

\section{conflicts \\ conflicts}

accident

Figure 2: Cognitive mapping of the words most frequently associated with alcohol consumption and its negative aspects.

(Source: Nasse, data analysis, 2019.) 
The lemmatization of the corpus on alcohol consumption and conflict types shows that the most common conflictual situations that occur in the context are household conflicts, followed by religious conflicts and street conflicts (See the following table 8).

Table 8

Words most frequently associated with alcohol consumption and conflict types.

\begin{tabular}{|l|l|}
\hline & \multicolumn{1}{|c|}{ Yes } \\
\hline & Conflicts (43) \\
Alcohol (23) \\
Consumption (23) \\
lemmatized corpus \\
Household conflicts (18) \\
Religious conflicts (9) \\
Street conflicts (16)
\end{tabular}

(Source: Nasse, data analysis, 2019.)

The diseases associated with alcohol consumption listed by the consumers (see the following table 9) are: liver disease (45\%), cancer (15\%), cardiovascular disease (10\%), diabetes (10\%), high blood pressure (10\%), and kidney disease (10\%).

Table 9

List of alcohol consumption related diseases.

\begin{tabular}{lccc} 
Diseases & Frequency & Relative frequency & Percentage \\
\hline Liver disease & 9 & 0.45 & $\mathbf{4 5 \%}$ \\
\hline Cancer & 3 & 0.15 & $\mathbf{1 5 \%}$ \\
\hline Cardiovascular disease & 2 & 0.10 & $\mathbf{1 0 \%}$ \\
\hline Diabetes & 2 & 0.10 & $\mathbf{1 0 \%}$ \\
\hline High blood pressure & 2 & 0.10 & $\mathbf{1 0 \%}$ \\
\hline Kidney disease & 2 & 0.10 & $\mathbf{1 0 \%}$ \\
\hline Total & $\mathbf{2 0}$ & $\mathbf{1}$ & $\mathbf{1 0 0 \%}$ \\
\hline
\end{tabular}

(Source: Nasse, qualitative data analysis, 2019)

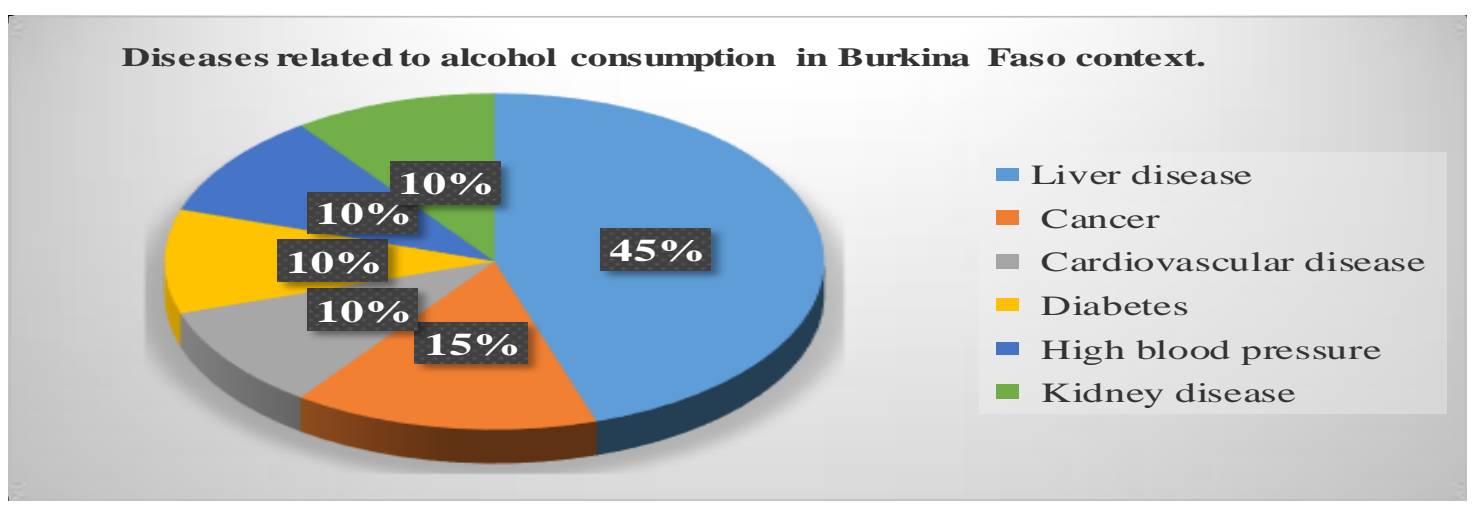

Figure 3: Diseases associated with alcohol consumption.

(Source: Nasse, data analysis, 2019).

\section{- Results analysis.}

After collecting the data, and after its transcription by hand an analysis of content is made to compare research propositions to the empirical data to see if they are confirmed or not. 
The results show that alcohol consumption is a source of street conflicts. For respondent 6, alcohol consumption causes street conflicts:

"First of all, alcohol consumption is a source of conflicts between people. For instance, someone who is always drinking alcohol without moderation may generate conflicts in the society. Second, alcohol consumption is a source of disease because some people have a liver disease, or other type of diseases due to the alcohol abuse'. Respondent 1 (Man, 38 years old).

The results show that alcohol consumption is a source of household conflicts. For respondent 4 , alcohol consumption generates conflicts in families:

"There are conflicts between husbands and wives; conflicts between a drunk wife and her husband and conflicts between a drunk husband and his wife. It creates conflicts between people who drink together at the drinking spot. There are some professional problems too, the boss will not give some responsibilities to a person who drink a lot and does not control himself or herself. It can also slow down the development of the country if a lot of people drink without consideration." Respondent 4 (Man, 29 years).

The results also show that alcohol consumption is a source of religious conflicts. For respondent 5, alcohol consumption is a source of religious conflicts:
"Moreover, alcohol can generate some conflicts in the religious context and in one way or in another way people can feel themselves as guilty but who is responsible of that situation." Respondent 5 (Man, 35 years old).

Some counter-intuitive results show that conflicts also affect alcohol consumption. To avoid conflicts some consumers moderate their consumption. An observation is that, conflictual situations may lead consumers to consume alcohol, and in that case some do consume to be in a state of somnolence, to get rid of their anger, their frustration or to forget the conflictual situation for a small period of time. Thus, conflicts also affect alcohol consumption in the context:

\footnotetext{
"One should moderate the consumption in order to avoid conflicts and the manufacturers should reduce the percentage of alcohol in the drinks.' Respondent 14 (Man, 42 years old).
} 
In addition, a grid of analysis is used to analyze the verbatim. According to Roche (2009, p. 49) a thematic grid of analysis helps to analyze the data and to bring out a synthesis on the themes. This analysis gives these results (see the following table 10 below).

Table 10

Content analysis of the verbatim with a grid of analysis.

\begin{tabular}{ll}
\hline \multicolumn{1}{c}{ Themes } & \multicolumn{1}{c}{ Synthesis } \\
\hline Theme 1: religious background. & $\begin{array}{l}\text { Respondents include the roman Christians and the evangelical } \\
\text { Christians. Religious similarities are source of communion and } \\
\text { sympathy between Christians, while religious differences (such as } \\
\text { consumption doctrines) is a source of disagreement. }\end{array}$ \\
\hline
\end{tabular}

Theme 2: understanding the Alcohol consumption is the drinking, the intake of a drink that contains concept of alcohol consumption. alcohol. It is sometimes accompanied with troubles, personal problems and social problems.

Theme 3: understanding of the A conflict is a disagreement, a tension, a misunderstanding between concept of conflicts. two individuals or a group of individuals that is marked by a violence, or an aggression.

Theme 4: consumption of alcohol.

Theme 5: types of alcohol. The respondents consume two types of alcohol: traditional alcohol and modern alcohol. Some also drink some counterfeit alcohol.

Theme 6: positive aspects of Alcohol is a source of socialization, jobs creation, income generation, alcohol consumption relaxation, and pleasure for consumers.

Theme 7: negative aspects of Alcohol is a source of mortal diseases, stigmatization, conflicts, alcohol consumption divorces, poverty, accidents and death.

Theme 8: conflicts associated to There are street conflictual circumstances, religious conflictual alcohol consumption. circumstances, and household conflictual circumstances.

Theme 9: suggestions to eradicate There should be an implication of the governmental authorities, an conflicts associated to alcohol implication of managers, an implication of manufacturers and an consumption. implication of religious leaders.

Theme 10: additional points. $\quad$ It is vital for the governmental authorities to take some measures to tackle unruly alcohol consumption and its conflictual situation.

Theme 11: personal traits The respondents are women and men from various social class and some of them are public employees, private employees or unemployed.

(Source: Nasse, data analysis, 2019.)

\section{Quantitative results analysis.}

The quantitative analysis shows that the total number of Christians in this research represents 241 respondents what is a sample of $100 \%$ of Christians (see the following figure 4).

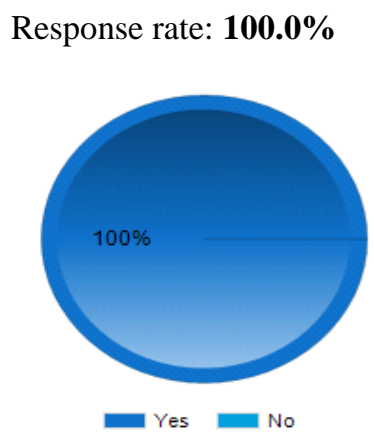

Figure 4: Christian respondents.

(Source, Nasse, data analysis, 2019) 
In addition, the respondents are all experienced alcohol consumers (see figure 5 below). They drink alcohol for some years. Unexperienced alcohol consumers are excluded.

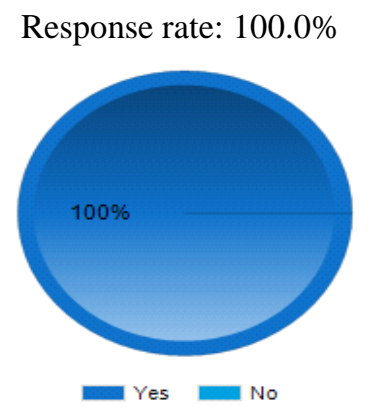

Figure 5: Respondents' experience as an alcohol consumer.

(Source, Nasse, data analysis, 2019)

For further, they are from different religious affiliation. 8.3\% are Assembly of God Christians, $\mathbf{5 . 8 \%}$ are Apostolic Christians, $\mathbf{1 3 . 7 \%}$ are Baptist Christians, $\mathbf{0 . 8 \%}$ are Centre International d' Evangelisation Christians, 2.9\% are Mennonite Christians, 13.3\% are Presbyterian Christians, $\mathbf{5 2 . 3 \%}$ are Roman Catholic Christians (see the following table 11 below).

Table 11

Respondents' Religious Affiliation.

\begin{tabular}{lccc} 
Religious affiliation & Frequency & Relative frequency & Percentage \\
\hline Assembly of God & 20 & $20 / 241$ & $\mathbf{8 . 3 \%}$ \\
\hline Apostolic & 14 & $14 / 241$ & $\mathbf{5 . 8 \%}$ \\
\hline Baptist & 33 & $33 / 241$ & $\mathbf{1 3 . 7 \%}$ \\
\hline Centre International d'Evangélisation & 19 & $19 / 241$ & $\mathbf{0 . 8 \%}$ \\
\hline Mennonite & 07 & $07 / 241$ & $\mathbf{2 . 9 \%}$ \\
\hline Presbyterian & 32 & $32 / 241$ & $\mathbf{1 3 . 3 \%}$ \\
\hline Roman catholic & 126 & $126 / 241$ & $\mathbf{5 2 . 3 \%}$ \\
\hline
\end{tabular}

(Source, Nasse, data analysis, 2019)

Furthermore, talking about the respondents' age, 20.25\% are between 18 and 25 years; $37 \%$ are between 26 and 35 years; $30.25 \%$ are between 36 and 45 years; and $12.5 \%$ are between 46 years and above. The respondents aged between 26 and 35 years are numerous because it is at this range that people follow the drinking fashion with a minimum of purchasing power. Besides, about the respondents' gender, $16.2 \%$ are women and $83.8 \%$ are men. The low rate of women could be explained by the fact that Christian female consumers are sometimes more stigmatized when they drink alcohol as compared to male consumers. Furthermore, about the respondents' marital status, $54.4 \%$ are single, $2.9 \%$ are engaged, $40.2 \%$ are married and $2.5 \%$ are divorced. Likewise, as regards to the respondents' profession, $17.5 \%$ are public employees, $51.7 \%$ are private employees, and $30.8 \%$ are unemployed. To add, on the subject of the respondents' social class, $1.5 \%$ are very poor, $52.5 \%$ are poor, $37.5 \%$ are rich, and $08.5 \%$ are very rich. On the subject of the respondents' educational level, $14.5 \%$ are illiterate, $12 \%$ have a primary school level, $24.1 \%$ have a secondary school level, and $49.4 \%$ have a university level. Concerning 
respondents' residence city, $100 \%$ of the respondents are living in the capital city of Ouagadougou. Finally, regarding the nationality, $97.5 \%$ of the respondents are Burkinabe, but $2.5 \%$ are not Burkinabe. These results are summarized on the following table 12.

Table 12

Statistics related to the socio-demographic variables.

\begin{tabular}{|c|c|c|c|c|}
\hline \multicolumn{2}{|c|}{ Socio-demographic variables } & Frequency & Relative frequency & Percentage \\
\hline \multirow{4}{*}{ Age } & $18-25$ & 49 & $49 / 241$ & $20.25 \%$ \\
\hline & $26-35$ & 89 & $89 / 241$ & $37 \%$ \\
\hline & $36-45$ & 73 & $73 / 241$ & $30.25 \%$ \\
\hline & 46- and above & 30 & $30 / 241$ & $12.5 \%$ \\
\hline \multirow[t]{2}{*}{ Gender } & Women & 39 & $39 / 241$ & $16.2 \%$ \\
\hline & Men & 202 & $202 / 241$ & $83.8 \%$ \\
\hline \multirow{4}{*}{ Marital status } & Single & 131 & $131 / 241$ & $54.4 \%$ \\
\hline & Engaged & 07 & $07 / 241$ & $2.9 \%$ \\
\hline & Married & 97 & $97 / 241$ & $40.2 \%$ \\
\hline & Divorced & 06 & $06 / 241$ & $2.5 \%$ \\
\hline \multirow{3}{*}{ Profession } & Public employees & 42 & $42 / 241$ & $17.5 \%$ \\
\hline & Private employees & 125 & $125 / 241$ & $51.7 \%$ \\
\hline & Unemployed & 74 & $74 / 241$ & $30.8 \%$ \\
\hline \multirow{4}{*}{ Social class } & Very poor & 4 & $4 / 241$ & $1.5 \%$ \\
\hline & Poor & 127 & $127 / 241$ & $52.5 \%$ \\
\hline & Rich & 90 & $90 / 241$ & $37.5 \%$ \\
\hline & Very rich & 20 & $20 / 241$ & $08.5 \%$ \\
\hline \multirow{4}{*}{ Education level } & Illiterate & 35 & $35 / 241$ & $14.5 \%$ \\
\hline & Primary school level & 29 & $29 / 241$ & $12 \%$ \\
\hline & Secondary school level & 58 & $58 / 241$ & $24.1 \%$ \\
\hline & University level & 119 & $119 / 241$ & $49.4 \%$ \\
\hline \multirow[t]{2}{*}{ City } & Ouagadougou & 241 & $241 / 241$ & $100 \%$ \\
\hline & Out of Ouagadougou & 0 & $0 / 241$ & $0.0 \%$ \\
\hline \multirow[t]{2}{*}{ Nationality } & Burkinabe & 235 & $235 / 241$ & $97.5 \%$ \\
\hline & Non Burkinabe & 06 & $06 / 241$ & $2.5 \%$ \\
\hline
\end{tabular}

(Source, Nasse, data analysis, 2019)

In this research there are three hypotheses to be verified.

The first alternative hypothesis $\left(\mathrm{H}_{1}\right)$ consists in finding out if there is a relationship between alcohol consumption and street conflicts. The corresponding null hypothesis is that there is not a relationship between alcohol consumption and street conflicts.

$\mathbf{H}_{1}$ : There is a relationship between alcohol consumption and street conflicts.

$\mathbf{H}_{\mathbf{0}}$ : There is not a relationship between alcohol consumption and street conflicts.

For the hypothesis testing, the correlations between the variables 'Alcohol consumption' and 'Street conflicts' is the method that is used. If the p-value, the khi-square value and the degree of freedom (dof) value are significant, then the null hypothesis is rejected and the alternative hypothesis is approved. The analysis of the data, shows that $\mathrm{p}=<\mathbf{0 . 0 1}$; Khi $2=\mathbf{5 4 . 2 0}$; dof $=\mathbf{1 5}$ 
(see the subsequent table 13). The p-value, the khi-square value and the degree of freedom (dof) value are very significant. Hence, the null hypothesis is rejected and the alternative hypothesis $\left(\mathrm{H}_{1}\right)$ is confirmed.

$H_{1}$ : There is a relationship between alcohol consumption and street conflicts.

The second alternative hypothesis $\left(\mathrm{H}_{2}\right)$ consists in finding out if there is a relationship between alcohol consumption and household conflicts. The corresponding null hypothesis is that there is not a relationship between alcohol consumption and household conflicts.

$\mathbf{H}_{2}$ : There is a relationship between alcohol consumption and household conflicts.

$\mathbf{H}_{\mathbf{0}}$ : There is not a relationship between alcohol consumption and household conflicts.

For the hypothesis testing, the correlations between the variables 'Alcohol consumption' and 'Household conflicts' is the method that is used. If the p-value, the khi-square value and the degree of freedom (dof) value are significant, then the null hypothesis is rejected and the alternative hypothesis is approved. The analysis of the data, shows that $p=\mathbf{0 . 0 0 9}$; Khi $2=\mathbf{3 1 . 0 0}$; dof $=\mathbf{1 5}$ (see the subsequent table 13). The p-value, the khi-square value and the degree of freedom (dof) value are very significant. Therefore, the null hypothesis is rejected and the alternative hypothesis $\left(\mathrm{H}_{2}\right)$ is confirmed.

$\mathrm{H}_{2}$ : There is a relationship between alcohol consumption and household conflicts.

The third, alternative hypothesis $\left(\mathrm{H}_{3}\right)$ consists in finding, if there is a relationship between alcohol consumption and religious conflicts. The corresponding null hypothesis is that there is not a relationship between alcohol consumption and religious conflicts.

$\mathbf{H}_{3}$ : There is a relationship between alcohol consumption and religious conflicts.

$\mathbf{H}_{\mathbf{0}}$ : There is not a relationship between alcohol consumption and religious conflicts.

For the hypothesis testing, the correlations between the variables 'Alcohol consumption' and 'Religious conflicts' is the method that is used. If the p-value, the khi-square value and the degree of freedom (dof) value are significant, then the null hypothesis is rejected and the alternative hypothesis is approved. The analysis of the data, shows that $\mathrm{p}=<\mathbf{0 . 0 1}$; Khi $2=\mathbf{3 8 . 5 6}$; dof $=\mathbf{1 5}$ (see the subsequent table 13). The p-value, the khi-square value and the degree of freedom (dof) value are very significant. Therefore, the null hypothesis is rejected and the alternative hypothesis $\left(\mathrm{H}_{3}\right)$ is confirmed.

$\mathrm{H}_{3}$ : There is a relationship between alcohol consumption and religious conflicts.

In a word, it is found that alcohol consumption is a source of conflicts. The analysis show that $\mathrm{p}$ $=<\mathbf{0 . 0 1}$; Khi $2=\mathbf{4 2 8 4 . 4 6}$; dof $=\mathbf{3 0 0}$. The $\mathrm{p}$-value, the khi-square value and the degree of freedom (dof) value are very significant. Therefore, there is a strong correlation between alcohol consumption and conflicts. It can be confirmed that alcohol consumption is a source of household conflicts. 
Table 13

Synthesis on the relation between the variables 'Alcohol consumption' and 'conflicts'.

\begin{tabular}{|c|c|}
\hline Variables crossing & $\underline{\text { Results }}$ \\
\hline "Alcohol consumption " and "Conflicts" & $\begin{array}{l}\mathrm{p}=<\mathbf{0 . 0 1} ; \text { Khi } 2=\mathbf{4 2 8 4 . 4 6} ; \text { dof }=\mathbf{3 0 0} \text {. } \\
\text { The relationship is very significant }\end{array}$ \\
\hline "Alcohol consumption " and "Household conflicts " & $\begin{array}{l}\mathrm{p}=\mathbf{0 . 0 0 9} ; \text { Khi } 2=\mathbf{3 1 . 0 0} ; \text { dof }=\mathbf{1 5} \text {. } \\
\text { The relationship is very significant. }\end{array}$ \\
\hline "Alcohol consumption" and "Street conflicts " & $\begin{array}{l}\mathrm{p}=<\mathbf{0 . 0 1} ; \text { Khi } 2=\mathbf{5 4 . 2 0} ; \text { dof }=\mathbf{1 5} . \\
\text { The relationship is very significant. }\end{array}$ \\
\hline "Alcohol consumption " and " Religious conflicts " & $\begin{array}{l}\mathrm{p}=<\mathbf{0 . 0 1} ; \text { Khi } 2=\mathbf{3 8 . 5 6} ; \text { dof }=\mathbf{1 5} \text {. } \\
\text { The relationship is very significant. }\end{array}$ \\
\hline "Conflicts " and "Alcohol consumption" & $\begin{array}{l}\mathrm{p}=<\mathbf{0 . 0 1} ; \text { Khi } 2=\mathbf{4 2 8 4 . 4 6} ; \text { dof }=\mathbf{3 0 0} \text {. } \\
\text { The relationship is very significant }\end{array}$ \\
\hline "Household conflicts " and "Alcohol consumption" & $\begin{array}{l}\mathrm{p}=\mathbf{0 . 0 0 9} ; \text { Khi } 2=\mathbf{3 1 . 0 0} ; \text { dof }=\mathbf{1 5} \text {. } \\
\text { The relationship is very significant. }\end{array}$ \\
\hline "Street conflicts " and "Alcohol consumption" & $\begin{array}{l}\mathrm{p}=<\mathbf{0 . 0 1} ; \text { Khi } 2=\mathbf{5 4 . 2 0} \text {; dof }=\mathbf{1 5} \text {. } \\
\text { The relationship is very significant. }\end{array}$ \\
\hline "Religious conflicts " and "Alcohol consumption" & $\begin{array}{l}\mathrm{p}=<\mathbf{0 . 0 1} ; \text { Khi } 2=\mathbf{3 8 . 5 6} ; \text { dof }=\mathbf{1 5} \text {. } \\
\text { The relationship is very significant. }\end{array}$ \\
\hline
\end{tabular}

(Source, Nasse, data analysis, 2019)

\section{- Additional quantitative data.}

The research also consisted in finding out if there are some moderator variables that could influence the relationship between alcohol consumption and street conflicts, the relationship between alcohol consumption and household conflicts, and the relationship between alcohol consumption and religious conflicts.

The correlations between the variables 'Alcohol consumption' and 'Gender' shows that the relationship is significant because $\mathrm{p}=\mathbf{0 . 0 4}$; Khi $2=\mathbf{2 5 . 7 5}$; dof $=\mathbf{1 5}$ (see the subsequent table 14). Then, the relationship between the variables 'Conflicts' and 'Gender' is not significant because $\mathrm{p}$ = 0.96; Khi $2=\mathbf{1 0 . 4 9}$; dof $=\mathbf{2 0}$.

To add, the relationship between the variables 'Household conflicts' and 'Gender' is not significant because $\mathrm{p}=\mathbf{0 . 5 2}$; Khi $2=\mathbf{1 4 . 0 4}$; dof $=\mathbf{1 5}$. For further, the relationship between the variables 'Street conflicts' and 'Gender' is slightly significant because $p=\mathbf{0 . 0 6}$; Khi2 $=\mathbf{2 4 . 3 4}$; dof $=\mathbf{1 5}$. In addition, the relationship between the variables 'Religious conflicts' and 'Gender' is very significant because $\mathrm{p}=\mathbf{< 0 . 0 1}$; Khi $2=\mathbf{1 4 3 . 5 4}$; dof $=\mathbf{4 5}$.

In a conclusion, the variable 'Gender' is not a moderator of the relationship between alcohol consumption and conflicts (see the subsequent table 14). 
Table 14

Synthesis on the relationship between the variables 'Gender', 'Alcohol consumption' and 'Conflicts'

\begin{tabular}{|c|c|}
\hline Variables crossing & Results \\
\hline "Alcohol consumption " and "Gender " & $\begin{array}{l}\mathrm{p}=\mathbf{0 . 0 4} ; \quad \text { Khi } 2=\mathbf{2 5 . 7 5} ; \quad \mathrm{dof}=\mathbf{1 5} \text {. } \\
\text { The relationship is significant. }\end{array}$ \\
\hline "Conflicts " and "Gender " & $\begin{array}{l}\mathrm{p}=\mathbf{0 . 9 6} ; \text { Khi } 2=\mathbf{1 0 . 4 9} ; \text { dof }=\mathbf{2 0} . \\
\text { The relationship is not significant. }\end{array}$ \\
\hline "Household conflicts " and "Gender" & $\begin{array}{l}\mathrm{p}=\mathbf{0 . 5 2} ; \text { Khi } 2=\mathbf{1 4 . 0 4} ; \text { dof }=\mathbf{1 5} \text {. } \\
\text { The relationship is not significant. }\end{array}$ \\
\hline "Street conflicts " and "Gender" & $\begin{array}{l}\mathrm{p}=\mathbf{0 . 0 6} ; \text { Khi } 2=\mathbf{2 4 . 3 4} ; \text { dof }=\mathbf{1 5} \text {. } \\
\text { The relationship is slightly significant. }\end{array}$ \\
\hline "Religious conflicts " and "Gender" & $\begin{array}{l}\mathrm{p}=<\mathbf{0 . 0 1} ; \text { Khi } 2=\mathbf{1 4 3 . 5 4} ; \text { dof }=\mathbf{4 5} \text {. } \\
\text { The relationship is very significant. }\end{array}$ \\
\hline
\end{tabular}

(Source, Nasse, data analysis, 2019)

The relationship between the variables 'Alcohol consumption' and 'Social class' is very significant because $\mathrm{p}=\mathbf{\mathbf { 0 . 0 1 }}$; Khi $2=\mathbf{1 4 7 . 5 8}$; dof $=\mathbf{4 5}$. Then, the relationship between the variables 'Conflicts' and 'Social class' is very significant because $\mathrm{p}=<\mathbf{0 . 0 1}$; Khi2 $=\mathbf{1 9 9 . 2 9}$; dof $=\mathbf{6 0}$ (see table 15 below).

To add, the relationship between the variables 'Household conflicts' and 'Social class' is very significant because $\mathrm{p}=\mathbf{< 0 . 0 1}$; Khi $2=\mathbf{1 1 0 . 4 3}$; dof $=\mathbf{4 5}$. For further, the relationship between the

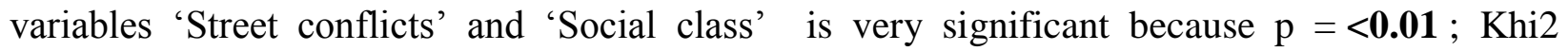
$=\mathbf{1 1 4 . 1 0}$; dof $=\mathbf{4 5}$. Besides, the relationship between the variables 'Religious conflicts' and 'Social class' is very significant because $\mathrm{p}=\mathbf{< 0 . 0 1}$; Khi $2=\mathbf{1 4 3 . 5 4}$; dof $=\mathbf{4 5}$. Thus, the variable 'Social class' is a moderator of the relationship between 'Alcohol consumption' and 'Conflicts'.

Table 15

Synthesis on the relationship between the variables 'Social class', 'Alcohol consumption' and 'Conflicts'.

\begin{tabular}{ll}
\multicolumn{1}{c}{ Variable crossing } & \multicolumn{1}{c}{ Results } \\
\hline "Alcohol consumption" and "Social class" & $\mathrm{p}=<\mathbf{0 . 0 1} ;$ Khi $2=\mathbf{1 4 7 . 5 8} ;$ dof $=\mathbf{4 5}$. \\
The relationship is very significant.
\end{tabular}

(Source, Nasse, data analysis, 2019)

A graph of relationships is generated and it shows that the different relationships are significant (see figure 6). As it is indicated on the subsequent figure 6, the different relationships between the variables are very significant. The variable 'Social class' moderates the relationship between 
the variable 'Alcohol consumption' and the variables, 'Street conflicts', 'Household conflicts', 'Religious conflicts'.

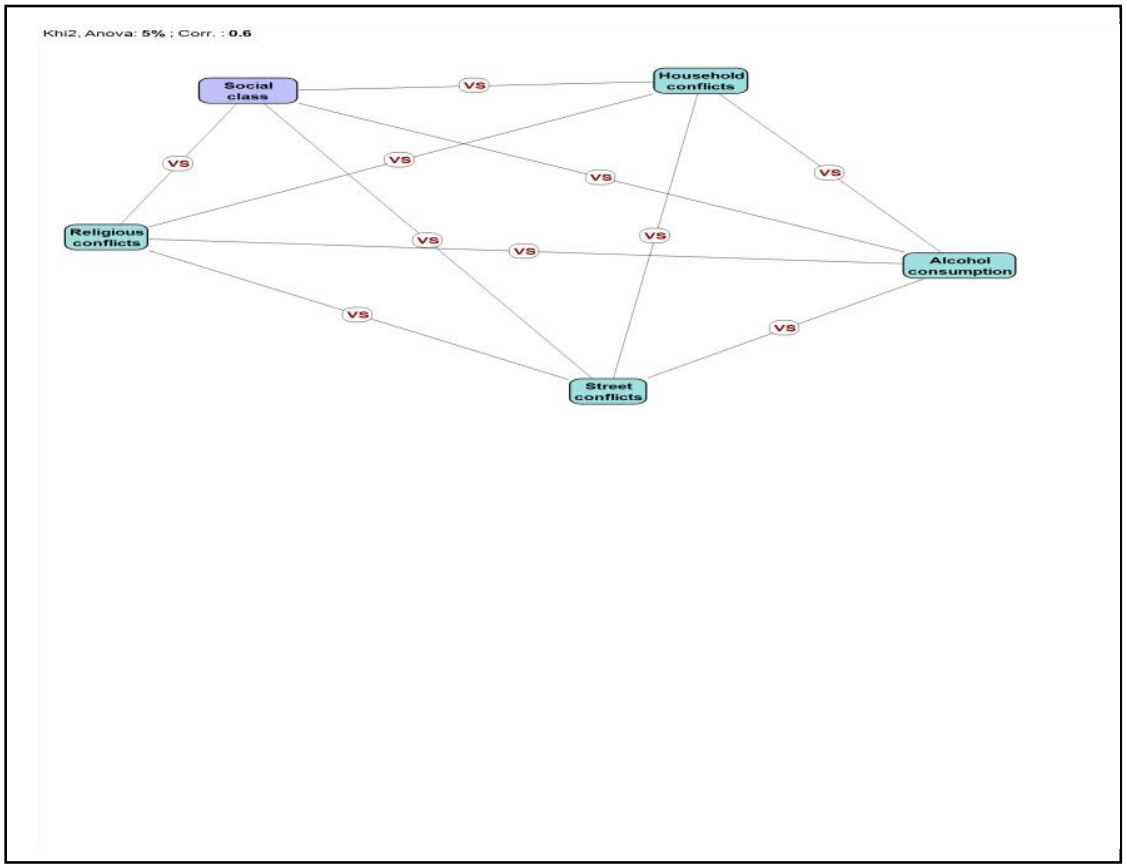

Figure 6: Graph of relationships between the different variables.

(Source, Nasse, data analysis, 2019)

\section{Multiple linear regression}

The linear regression consists in producing as accurately as possible the equation to calculate the value of the variable to explain. This can thus help to determine not only the variable that have no influence (as they do not appear in the equation) but also the contribution of other variables by measuring their influence on the explanatory variable.

\section{- $\quad$ The equation of the model.}

The equation of the model is in the following form :

$Y_{i}=a+b_{1} X_{1}+b_{2} X_{2}+\ldots b_{n} X_{n}+e$ (Carricano et al, 2010, p.162).

$\mathrm{Y}_{\mathrm{i}}=$ alcohol consumption

$\mathrm{a}=$ constant

$\mathrm{X}_{1}=$ disagreement with religious leaders

$\mathrm{X}_{2}=$ street violence

$\mathrm{X}_{3}=$ high risk of religious conflicts

$\mathrm{X}_{4}=$ fighting with people in the religious community 
$\mathrm{X}_{5}=$ disagreement with people in the street

$\mathrm{X}_{6}=$ violence in the religious environment

$\mathrm{X}_{7}=$ high risk of street conflicts

$\mathrm{X}_{8}=$ fighting with people in the street

$\mathrm{X}_{9}=$ disagreement with people in the household leaders

$\mathrm{X}_{10}=$ household violence

$\mathrm{X}_{11}=$ high risk of household conflicts

$\mathrm{X}_{12}=$ fighting with people in the household

$\mathrm{X}_{13}=$ age

$\mathrm{X}_{14}=$ Social class

$\mathrm{e}=$ error

The results bring out the following equation of the model :

Alcohol consumption $=1.11+0.18 *$ high risk of street conflicts $+0.31 *$ disagreement with people in the household $-0.21 *$ household violence $+0.40 *$ fighting with people in the household - $0.14 *$ Social class.

This equation shows that the most influential parameters are five (5) (see table 16 below). The data related to the significance of these parameters are :

-high risk of street conflicts: coefficient $=0.18$; $\mathrm{p}$-value $=0.01$.

- dis bagreement with people in the household: coefficient $=0.31$; $\mathrm{p}$-value $=<0.01$.

-household violence: coefficient $=-0.21 ; \mathrm{p}$-value $=<0.01$.

-fighting with people in the household: coefficient $=0.40$; $\mathrm{p}$-value $=<0.01$,

-social class: coefficient $=-0.14 ; \mathrm{p}$-value $=0.02$.

Table 16

Influence of explanatory variables.

\begin{tabular}{|c|c|c|c|c|}
\hline & Coefficient & p-value & Standardized coefficient & Contribution \\
\hline Const & 1.11 & $<0.01$ & - & - \\
\hline $\begin{array}{l}\text { High risk of street } \\
\text { conflicts }\end{array}$ & 0.18 & 0.01 & 0.18 & 14.63 \\
\hline $\begin{array}{l}\text { Disagreement with } \\
\text { people in the household }\end{array}$ & 0.31 & $<0.01$ & 0.35 & 29.03 \\
\hline Household violence & -0.21 & $<0.01$ & -0.20 & -16.67 \\
\hline $\begin{array}{l}\text { Fighting with people in } \\
\text { the household }\end{array}$ & 0.40 & $<0.01$ & 0.36 & 29.70 \\
\hline Social class & -0.14 & 0.02 & -0.12 & -9.97 \\
\hline
\end{tabular}

The equation shows that there are five (5) parameters that explain $43.31 \%$ of the variance of the variable to be explained that is alcohol consumption. The equation also reveals that the parameters without influence are nine (9). The nine (9) parameters that do not contribute to the explanation (at threshold of 5\%) are: age, street violence, fighting with people in the religious 
community, disagreement with people in the street, violence in the religious environment, high risk of street conflicts, fighting with people in the street, high risk of household conflicts.

\section{- Quality of the estimate.}

The model accounts for $\mathbf{4 3 . 3 1 \%}$ of the variance of the variable to be explained, with a coefficient of the multiple correlation $\mathrm{R}=\mathbf{0 . 6 6}$; a $\mathrm{p}$-value of $\mathrm{R}$ : $\mathrm{p}(\mathrm{R})=<\mathbf{0 . 0 1}$; a coefficient of fisher $F=35.91$, and a $p$-value of $F: p(F)=<\mathbf{0 . 0 1}$. The representation of the $Y$ estimated of the equation of the model are shown on the following figure 7.

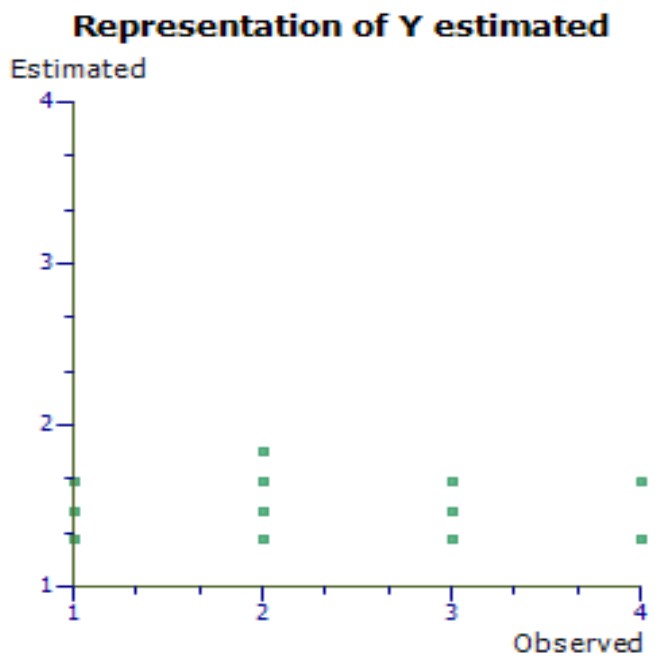

Ideally all the points are on the line (100\% of the variable is explained).

Figure 7: Representation of the Y estimated of the equation of the model.

(Source, Nasse, data analysis, 2019)

\section{Discussion of the results.}

Some studies slightly point out that in the context of Burkina Faso that industrial alcohol consumption may be a trigger of social conflicts consumers (Nasse, Ouédraogo, \& Diop, 2016) however in the present research clearly show that alcohol consumption in the context of Burkina Faso is a source of street conflicts. For further, the correlation between the variables alcohol consumption and street conflicts is very significant. Thus, the first proposition or first hypothesis is confirmed.

P1 or H1: There is a relationship between alcohol consumption and street conflicts.

The results show that alcohol consumption in the context of Burkina Faso is a source of misunderstanding in families. Some previous studies slightly underline that alcohol consumption is a source of domestic violence by men against women in the African context (Dery and Diedong, 2014). The present research clearly shows that alcohol consumption brings household conflictual situation such as conflict of the same gender (men and men, women and women) and conflicts of different gender (men and women, women and men). Thus, there are some conflictual situations between some family members. In addition, the correlation between the variables alcohol consumption and household conflicts is very significant. Therefore, the second proposition or the second hypothesis is confirmed. 
P2 or H2: There is a relationship between alcohol consumption and household conflicts.

Some previous studies in the context, show that industrial alcohol consumption may be a trigger of conflicts between religious leaders and the unruly consumers (Nasse, Ouédraogo, \& Diop, 2016), when the drinking spot is closer to a worship place. The present research clearly shows through the answers given by respondents that alcohol consumption is a source of religious conflicts. For further, the correlation between the variables alcohol consumption and religious conflicts is very significant. Thus, the third proposition or the third hypothesis is confirmed.

P3 or H3: There is a relationship between alcohol consumption and religious conflicts.

The following table 17 shows the different hypotheses or propositions that are confirmed.

Table 17

Synthesis on proposition or hypotheses confirmation.

\begin{tabular}{ccl}
\hline Research hypothesis or proposition & $\begin{array}{c}\text { Significance of the relationship } \\
\text { between variables based on } \\
\text { correlations and the p-value }\end{array}$ & $\begin{array}{l}\text { Confirmation } \\
\text { status }\end{array}$ \\
\hline Hypothesis 1 or proposition $\mathbf{1}$ & The relationship is very significant & Confirmed \\
\hline Hypothesis $\mathbf{2}$ or proposition $\mathbf{2}$ & The relationship is very significant & Confirmed \\
\hline Hypothesis 3 or proposition $\mathbf{3}$ & The relationship is very significant & Confirmed \\
\hline$*: \mathbf{P}<\mathbf{0 . 0 5}$ & & \\
\hline
\end{tabular}

(Source: Nasse, data analysis, 2019.)

\section{CONCLUSION.}

There are different research contributions: the conceptual contributions, the methodological contributions, the theoretical contributions, and the managerial contributions. The next lines start with the presentation of the conceptual contributions.

\section{Conceptual contributions.}

The main conceptual contributions are based on the enrichment the literature on alcohol consumption and conflicts. Previous literature reviews have brought out some definitions on the concepts that are redefined here in the Western context, in the Asian context, and, in the African context. However, these concepts are discussed, analyzed and enriched again in the context of Burkina Faso to better redefine them due to some specific needs related to their understanding and to their use.

\section{Methodological contributions.}

In terms of methodological research contributions, it is essential to recognize a creation of new tools that help to categorize the socio-cultural context of Burkina Faso.

\section{Theoretical contributions.}

Regarding, theoretical contributions, this research confirms that alcohol consumption leads to household conflicts, street conflicts, religious conflicts. However, the responsible factors for alcohol consumption or the intensification of alcohol consumption are different from other contexts; they have their origin in some cultural factors (Durmaz, Reyhan, \& Mücahit, 2011; Nayeem, 2012; Nasse \& al., 2016), extreme poverty, poor conditions of living, ignorance, 
sexuality, a very poor management situation, a lack of serious control of the consumption sector by the authorities, social frustrations, pre-conflict factors, the lack of a strong implication of religious leaders, the lackof an implictaion of educators and a lack of an appropriate sensitization about moderation in alcohol consumption. Thus, this research leads to new theoretical findings that are unique to the Burkinabe cultural context.

\title{
Managerial contributions.
}

Regarding the managerial contributions of the research, it aims to draw out both some tangible conflicts and some intangible conflicts (intra-religious and inter-religious conflicts) related to the consumption of industrial drinks (Nasse \& al., 2019) and to see how these issues can be addressed in the Burkina Faso context. It also brings out the inequalities and the inequities that are related to the production and consumption of alcohol drinks in order meet the expectations and needs of the consumers. For instance, the consumers spend their money to consume alcohol but still they are victims of the negatives effects of the counterfeit alcohol that is produce by manufacturers. Here are some answers given by some consumers about the negative effects of counterfeit alcohol:

\begin{abstract}
"I would like to thank you for the time you took to interchange but one thing I want to mention is that there is this drinking spot where the owner if selling counterfeit alcoholic drinks and people are drinking it they are and dying; and the owner does not care what is important for him is that he is making a lot of money. So, I think that this interview is a good thing; and it should push us to rethink our policies in term of goods such as alcohol importation. I think that the interview that is being made should have a final report that should be given to the authorities so that they will regulate the importation of these alcoholic drinks. It should also bring out some information with a good notion and a good culture about alcohol consumption.' Respondent 8(Man, 36 years old).
\end{abstract}

Furthermore, the answers given by the respondents are focused on the fact that manufacturers should abide to the norms of qualitative products in order to meet consumers' expectations and satisfaction. Answers from respondent 2, show that manufacturers should revise both quality and prices:

"Yeah, the authorities should work against the bad alcohol drinks that entering in the country. There should be a control about the bad quality of alcohol. Authorities and the manufacturers should also raise the prices of alcohol drinks in Burkina. If it is expensive people will not be drunk. I am happy because this study will raise what is a taboo in the Christian religion and it will help us to solve the issue of alcohol in the society." Respondent 2(Man, 34 years old). 
In addition, the consumers have mentionned some negative aspects of alcohol consumption due to the lack of moderation in term of consumption:

\begin{abstract}
"The abuse of alcohol brings someone to be drunk what is not good for the family as it generates conflicts, and that also brings weakness to the body and also people may not consider you in some places. The abuse of alcohol also can make the consumer to be sick, abusing alcohol bring diseases. I think that it is personal; I am able to drink two, but another consumer is able to drink only one alcohol bottle; some are able to drink three bottles without being drunk."' Respondent 12(Man, 46 years old).
\end{abstract}

Therefore, managers should also help towards the sensitization through ads, and also through a notice on packaging. Nasse et al. (2016) underline that only some few companies in the beverage sector have a notice on their packaging to sensitize the consumer about moderation in term of alcohol consumption. This will help to reduce the conflictual situations in the context. It will also help to reduce the rate of mortality and the rate of morbidity in Burkina Faso, because some previous studies have shown that excess in alcohol consumption generates physical health damage (Valentine, Jayne, Gould, \& Keenan, 2010, p. 42).

Some counter-intuitive results show that conflicts also affect alcohol consumption. To avoid conflicts some consumers have chosen to moderate their consumption. Conflictual situations may lead consumers to consume alcohol. Thus, conflicts also affect alcohol consumption:

"One should moderate the consumption in order to avoid conflicts
and the manufacturer should reduce the percentage of alcohol in
the drinks because it is difficult for people not to drink."
Respondent 14 (Man, 42 years old).

The research model proposed at the beginning of this research is reshaped after the findings (see figure 8 below).

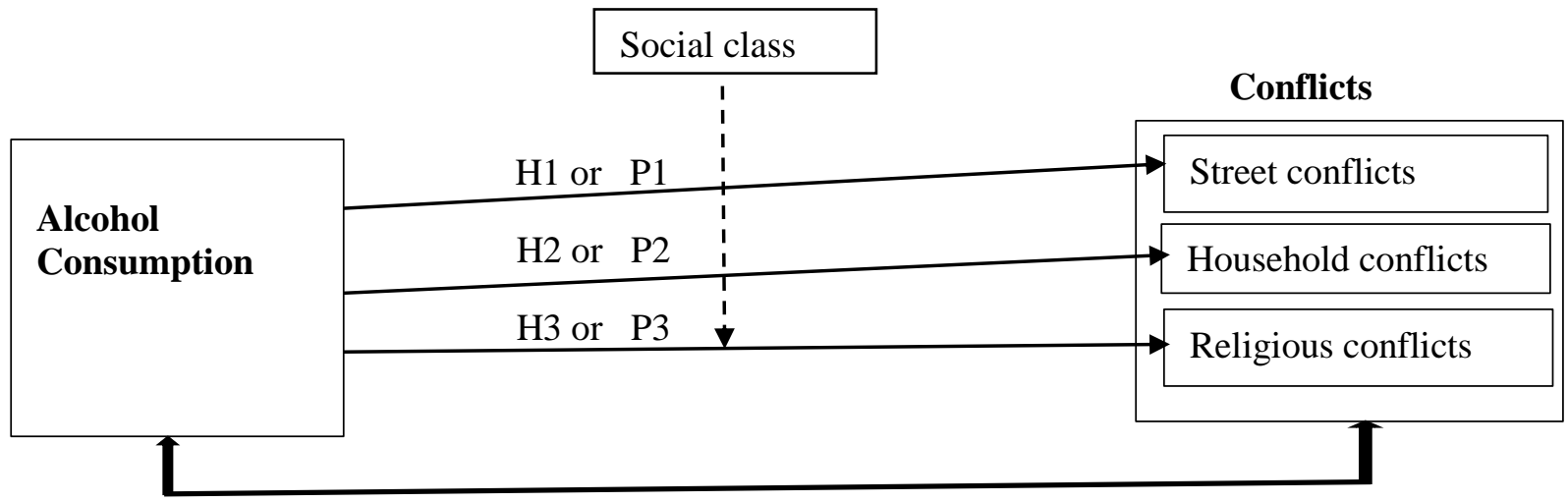

Figure 8: Research model reconsidered.

(Source: Nasse, research model, 2019) 
The consumption of alcohol is always perceptible in the context of Burkina Faso. It generates conflicts such as street conflicts, household conflicts, and religious conflicts. Some consumers of alcohol contribute to generate conflicts by an unethical consumption and by a lack of moderation. The present research also provides the different implications in relation with the findings.

\section{Findings and Implications.}

The Roman Catholic consumers are numerous in Burkina Faso because Roman Catholic Christians are tolerant towards alcohol consumption (Nasse, 2018) and due to their dominant number in term of statistics. However, the Roman Catholic consumption culture requires that Christian drink alcohol moderately. The limited number of evangelical Christians could be explained by the fact that evangelical Christians are not tolerant towards alcohol consumption (Nasse, 2018) and their small number in term of statistics. Most of the evangelical doctrines condemns alcohol consumption even if some of them are a little bit tolerant towards alcohol consumption. This research shows that alcohol consumption is at the base of household conflicts, religious conflict, and street conflicts. Therefore, it is crucial for the political authorities, the educators and the religious authorities to involve themselves in sensitizing the consumers to moderate their alcohol consumption to avoid conflicts but also to keep their health. Some previous studies have shown that exaggeration in consumption is a source of diseases (Kunfaa, 1996; Cole, 2015; Nasse, 2018). Thus, it is very useful for the authorities in Burkina Faso to put some measures to stop the counterfeit alcoholic beverages that is a harm to the consumers. Counterfeit alcohols are invading the market and their production do not respect quality norms. Some counterfeit alcohols have killed several consumers, particularly consumers who are from the very poor social class or poor social class. Thus, governmental authorities and managers should take some appropriate measures to tackle the counterfeit alcohol production, not only by increasing market control, but also by requesting some quality standards and norms in term of alcohol production and sales. For further, alcohol consumption by youth is often combined with some harmful products such as strong drugs and destructive substances (Picard-Masson, 2014; Nasse, 2018). The findings imply that the governmental authorities include alcohol education as part of the curriculum in schools (Valentine, Jayne, Gould, \& Keenan, 2010), to help sensitize the younger generations. It is also vital to tackle alcohol consumption by the youth especially the teenagers with some appropriate measures to avoid some negative consequences that destroy the future generation.

In Africa management lacks innovation (Bourgoin, 1984), thus, it is good for managers to set some good management strategies (Ouédraogo, 2007) that respond to the need of the consumers, and that create an environment where conflict prevention mechanisms are well monitored (Aasoglenang \& Baataar, 2012). There is a need for a rigorous segmentation of alcoholic drinks market by giving opportunities for consumers to have some low alcoholic beverages. There is also a need to protect the environment with some rigourous policies that focus on corporate social responsibility. It will help to reduce environmental pollution by unruly consumers who throw alcohol packaging everyhwere. 


\section{Future research.}

It would be helpful to extend this research to other research areas or to extend it to some other African countries to see whether the results are the same.

\section{Conflict of interests.}

The author has not declared any conflict of interests.

\section{Acknowledgements.}

The author would like to thank the German authorities and the DAAD program( Grant Number :17000736), the University for Development Studies, the Ouaga 2 University, the Saint Thomas d'Aquin University, the New Dawn University, Ancestry Azaaban (AZ), Global Impact Services (GIS), Fukunaga Architects Engineers (FAE), Bethel Hamliri, and all the persons who have contributed to this research.

\section{References.}

Aasoglenang, T. A., \& Baataar, C. (2012). Decentralized planning for pre-conflict and postconflict management in the Bawku municipal assembly of Ghana. Ghana Journal of Development Studies, 9(2), 63-79.

Alam, S.S., Mohd, R., \& Hisham, B. (2011). Is religiosity an important determinant on Muslim consumer behaviour in Malaysia? Journal of Islamic Marketing, 2(1), 83-96.

Al-Hyari, K., M., Alnsour, G., Al-Weshah, \& Haffar, M. (2012). Religious beliefs and consumer behaviour: from loyalty to boycotts. Journal of Islamic Marketing, 3(2), 155-174.

Amankwaa, A. A., W., Reed, \& Owens, De' A. (2012). Church attendance and alcohol consumption level: reasons for not drinking alcohol among college students. International Journal of Humanities and Social Science, 2(4), 1-8.

Andaleeb, S. S. (1993). Religious affiliations and consumer behavior: an examination of hospitals. Journal of Health Care Marketing, 13(4), 42-49.

Anderson, D. R., Sweeney, D. J., Williams, T. A., Camm, J. D., \& Cochran, J. J. (2015). Statistiques pour l'économie et la gestion. (5 ${ }^{\text {ème }}$ éd.). Paris, PA: Distribution Nouveaux Horizons.

Awedoba, A. K. (2011). An ethnographic study of Northern Ghanaian conflicts: towards sustainable peace. Accra, AC: Sub-Saharan Publishers.

Bailey, J. M., and Sood, J. (1993). The effect of religious affiliation on consumer behavior: a preliminary investigation. Journal of Managerial, 3(5), 328-352.

Bagozzi, R., Abe, S., Wong, N., \& Bergami, M. (2000). Cultural and situational contingencies and the theory of reasoned action: application to fast food restaurant consumption. Journal of Consumer Psychology, 92(2), 97-106.

Bandura, A. (1977). Social learning theory. New Jersey, NJ: Prentice Hall.

Banyte, J., \& Matulioniene, L. (2005). The singularities of the cultural element in consumer behavior. Innovative Marketing, 1(1), 33-39. 
Bazié, J. (2011). Comprendre la communication en milieu traditionnel. Ouagadougou, OU : Les Presses Africaines.

Benabdallah, M., \& Jolibert, A. (2013). L'acculturation : l'influence des sous-cultures d'origine et de la distance culturelle. Décisions Marketing, 72(1), 179-205.

Berger, A. (1997). Population, consumption, and the environment: religious and secular responses. Journal of Hindu-Christian Studies, 10(2), 2-4.

Bidan, M. (2010). Systèmes d'information et développement durable : modèles théoriques et pratiques organisationnelles. Management et Avenir, 9(39), 304-306.

Bourgoin, H., (1984). L'Afrique malade du management. Paris, PA : J. Picollec.

Campanella, M. R. (2016). Halal food consumption, responsibility, moral overtones and renegotiation of categories among Muslim believers in Stockholm County. Uppsala, UP: University of Uppsala.

Cleveland, M., Laroche, M., \& Hallab, R. (2010). Globalization, culture, religion, and values: comparing consumption patterns of Lebanese Muslims and Christians. Ontario, ON: University of Western Ontario.

Cole, H. (2015). Factors influencing the association between religiosity and drinking behavior in underage college students. University of Kentucky, Theses and Dissertations-Psychology, 54(1), 1-48.

Coyne, I. T. (1997). Sampling in qualitative research. Purposeful and theoretical sampling: merging or clear boundaries? Journal of Advanced Nursing, 26(1), 623-630.

Creswell, J. W. (2009). Research design: qualitative, quantitative and mixed methods approach. California, CA: Sage Publication.

De Mooij, M. (2003). Convergence and divergence in consumer behaviour: implications for global advertising. International Journal of Advertising, 22(2), 183-202.

Dery, I., \& Diedong, A. L. (2014). Domestic violence against women in Ghana: an exploratory study in Upper West Region, Ghana. International Journal of Humanities and Social Science, 4(12), 228-244.

Diop, F. (2004). L'achat familial en Afrique. Dakar, DA : École Supérieure Polytechnique de Dakar, Université Cheikh Anta Diop.

Diop, F. (2012). L'influence de la religion musulmane sur le comportement de consommation au Sénégal. Dakar, DA : École Supérieure Polytechnique de Dakar, Université Cheikh Anta Diop.

Dollard, J., Miller, N. E., Doob, L. W., Mowrer, O. H., \& Sears, R. R. (1939). Frustration and aggression. New Haven, NH: Yale University Press.

Durmaz, Y., Reyhan, O., \& Mücahit, C. (2011). The impact of cultural factors on the consumer buying behaviors examined through an empirical study. International Journal of Business and Social Science, 2(5), 109-114.

Essoo, N., \& Dibb, S. (2004). Religious influences on shopping behaviour: an exploratory study. Journal of Marketing Management, 20(7/8), 683-712.

Fam, K. S., Waller, D. S., \& Erdogan, B. Z. (2002). The influence of religion on attitudes towards the advertising of controversial products. European Journal of Marketing, $38(5 / 6), 537-555$. 
Fred-Mensah, B. K. (2005). Ideas, power, and multilateral institutions. International Studies Review, 7(1), 84-86.

Ganassali, S. (2009). Les enquêtes par questionnaires avec sphinx. Paris, PA: Pearson Éducation.

Ger, G. (2005). Religion and consumption: the profane sacred. Advances in Consumer Research, 32(44), 79-81.

Heiman, A., Zilberman, D., \& Gordon B. (2001). Religion, religiosity, lifestyles and food consumption. Agribusiness, an International Journal, 17(4), 455-468.

Hejase A. J. \& Hejase H. J. (2013). Research methods, a practical approach for business students (Second ed.). Philadelphia, PH : Masadir Inc.

Institut national de la statistique et de la démographie, (2010). Recensement général de la population et de l'habitat 2006, rapport définitif, Ouagadougou, Burkina Faso.

Jung, K., \& Kau, A. K. (2004). Culture's influence on consumer behaviors: differences among ethnic groups in a multiracial Asian country. Advances in Consumer Research, 31(1), 366-372.

Khalla, S. (2006). Relation au sacré et fidélité à la marque. Thèse de Doctorat ès Sciences de Gestion. Caen, CA : Université de Caen.

Kibora, L. (2015). Social change, new food habits and food price volatility in Burkina Faso. IDS Bulletin, 46(6), 105-109.

Kitchathorn, P. (2009). Factor influencing customer repurchase intention: an investigation of switching barriers that influence the relationship between satisfaction and repurchase intention in the low-cost airlines industry in Thailand. Adelaide, AD: University of South Australia.

Kunfaa, E. Y. (1996). Sustainable rural health services through community-based organisations: women's groups Ghana. Dortmund, DO: Spring Research Series No. 16, University of Dortmund.

Le Petit Larousse Illustré, (2006). Langue : français. Paris, PA: Éditions Larousse.

Livian, Y. F., \& Shamba, P. B. (2014). Le management africain introuvable : pour une approche de l'hybridité segmentée. Marseille, MA: Communication pour la 4ème Conférence Atlas-AFMI.

Lord, R. K., \& Putrevu, M. (2005). Religious influence on consumer behavior: classification and measurement. Advances in Consumer Research, 32(184), 651 -652.

Marfo, S., \& Musah, H. (2018). Examining the position of the chieftaincy institution in modern political system of Ghana. Journal of Sociology and Social Work, 6(1), 64-72.

Mansori, S. (2012). Impact of religion affiliation and religiosity on consumer innovativeness: the evidence of Malaysia. World Applied Sciences Journal, 17(3), 301-307.

Marshall, M. N. (1996). Sampling for qualitative research. Family Practice, 13(6), 522-525.

Mokhlis, S. (2006). The effect of religiosity on shopping orientation: an exploratory study in Malaysia. The Journal of American Academy of Business, 9(1), 64-74.

Mokhlis, S. (2008). Consumer religiosity and the importance of store attributes. The Journal of Human Resource and Adult Learning, 4(2), 122-133. 
Mokhlis, S. (2009). Relevancy and measurement of religiosity in consumer behavior research. International Business Research, Management Trade, 2(3), 75-84.

Mokhlis, S. (2010). Religious contrasts in consumer shopping styles: a factor analytic comparison. Journal of Business Studies Quarterly, 2(1), 52-64.

Morse, J. M. (1991). Strategies for sampling in qualitative nursing research: a contemporary dialogue. California, CA: Sage.

Morsy, S., \& Néji, B. (2016). Innovativité et religiosité : cas de la consommation alimentaire en Tunisie. Proceedings of the Marketing Spring Colloquy (MSC), Unit of Research \& Applications in Marketing (URAM) 7(1), 193-212.

Mustafar, M. Z., \& Borhan, J. T. (2013). Muslim consumer behavior: emphasis on ethics from Islamic perspective. Middle-East Journal of Scientific Research, 9(18), 1301-1307.

Nasse, B. T. (2006). Kasim borrowings from English: an evidence from Burkina Faso. A master thesis. Ouagadougou, OU: University of Ouagadougou.

Nasse B. T. (2012). How to succeeding in Church missionarial work in West Africa. Saarbrücken, SA: Lambert Academic Publishing.

Nasse, B. T. (2016). L'équité interne dans la gestion de la relation client : une étude comparative quantitative de trois entreprises privées du Burkina Faso. Université Aube Nouvelle, Journal Ouest-Africain des Sciences de Gestion, 1(1), 38 -54.

Nasse, B. T., Ouédraogo, A. \& Diop, F. (2016). L'influence de la religiosité sur les comportements des consommateurs à l'égard des boissons industrielles non alcoolisées : une étude quantitative et une étude qualitative portant sur les musulmans dans le contexte du Burkina Faso. Journal Ouest Africain de Sciences de Gestion, 1(2), 1-28.

Nasse, B. T. (2018). Pratiques religieuses et comportement de consommation dans un contexte africain : une étude exploratoire sur les consommateurs au Burkina Faso. Thèse de Doctorat en sciences de Gestion, spécialité marketing. Ouagadougou, OU : Université Aube nouvelle en cotutelle avec l'Université Cheikh Anta Diop.

Nasse, B. T., Ouédraogo, A. \& Diop, F. (2019). Religiosity and consumer behavior in developing countries: An exploratory study on Muslims in the context of Burkina Faso. African Journal of Business Management, 13(4), 116-127.

Nayeem, T. (2012). Cultural influences on consumer behavior. International Journal of Business and Management, 7(21), 79-91.

Nurbasari, A. (2015). The impact of spiritual marketing on consumer behavior in choosing halal food: case study on moslim community in Bandung. Al Hijaz International Refereed Journal for Islamic and Arabic Studies, 273(10), 271-306.

Ouédraogo, A. (2007). Strategic management in African firms: a local perspective. Problems and Perspectives in Management, 5(1), 82-94.

Patel, M. (2010). Influence of religion on shopping behaviour of consumers-an exploratory study. National Monthly Refereed Journal of Research in Commerce and Management, $1(5), 68-78$.

Picard-Masson, M. (2014). Les liens entre la consommation de boissons énergisantes et la consommation de psychotropes chez les jeunes : que connaissons-nous du phénomène ? Drogues, Santé et Société, 13(2), 1-25. 
Porter, C. (2013). The religion of consumption and Christian neighbor love. Chicago, CH: Loyola University.

Quivy, R., \& Van Campenhoudt, L. (2011). Manuel de recherche en sciences sociales (2 ${ }^{\mathrm{ème}}$ éd.). Paris, PA: Dunod.

Roche, D. (2009). Rédiger son mémoire avec succès. Paris, PA: Eyrolles, Éditions d'Organisation.

Ruzeviciute, R., \& Ruzevicius, J. (2011). Consumption culture in the presence of globalisation: the influence of religion, nation and ethnicity on consumption patterns. Ekonomika, 90(4), 150-163.

Sow, D. M. (2005). Alimentation et boissons au Burkina Faso : au-delà de la survie. Genève, GE : Bureau International du Travail. Suisse.

The United Bible Society, (1994). Good news Bible. New York, NY : Bible Societies, Harper Collins.

Usinier, J. C. (2000). Marketing across cultures ( $3^{\text {rd }}$ ed.). London, LO: Pearson Education.

Valentine, G., Jayne, M., Gould, M., \& Keenan, J. (2010). Family life and alcohol consumption: A study of the transmission of drinking practices. Joseph Rowntree Foundation, 1(1), 459.

Van Den Bergh, J., \& Nijkamp, P. (1991). Operationalizing sustainable development: dynamic ecological economic models. Ecological Economics, 4(1), 11-33.

Van Laethem, N., \& Body, L. (2008). Le plan marketing (2 ${ }^{\text {ème } e ́ d .) . ~ P a r i s, ~ P A: ~ D u n o d . ~}$ 